\title{
Formação continuada de professores: avanços permeados no programa Pacto em cinco escolas públicas estaduais da região central do $\mathrm{RS}$
}

\author{
Continuous Teacher Training: advances permeated \\ in Pact program in five public state schools \\ in the central region of RS
}

\section{Formación continuada de profesores: avances impregnados en el programa Pacto en cinco escuelas públicas estatales de la región central del RS}

\author{
Alexandre Giacomini \\ Universidade Federal de Santa Maria (UFSM), Santa Maria/RS - Brasil \\ Everton Lüdke \\ Universidade Federal de Santa Maria (UFSM), Santa Maria/RS - Brasil
}

\begin{abstract}
Resumo
Este trabalho, de caráter qualitativo, investiga a temática da formação continuada de professores do Programa Pacto, em cinco escolas públicas estaduais da região central do estado do Rio Grande do Sul, abrangidas pela 24a Coordenadoria Regional de Educação (CRE), durante os anos de 2014 e 2015. A empiria visa a analisar avanços que permearam este processo formativo, por meio da opinião de 25 professores e de cinco orientadores de estudo. A coleta de dados ocorreu por meio da observação direta individual não participante anotada no diário de bordo, da análise documental e da entrevista semiestruturada. Os resultados apontaram a construção de quatro categorias: o Programa Pacto na visão dos educadores, as expectativas do Pacto, as atividades/metodologias desenvolvidas e o papel do orientador de estudos e sua formação.
\end{abstract}

Palavras-chaves: Formação Continuada de Professores, Programa Pacto, Formação em serviço, Locus da escola

\begin{abstract}
This qualitative work investigates the topic of the continuous teacher training of the Pact Program in five state public schools in the central region of Rio Grande do Sul state, covered by the $24^{\text {th }}$ Regional Education Coordination (CRE), during the years of 2014 and 2015. The empiric aims to analyze advances that have permeated this formation process, through the opinion of 25 teachers and 5 study advisors. The data collection was done through direct non-participant individual observation wrote down in the logbook, the documentary analysis, and the semi-structured interview. The results have pointed the construction of four categories: the Pact Program in the view
\end{abstract}


of the educators, the expectations of the Pact, the activities/methodologies developed, and the role of the study supervisor and their training.

Keywords: Teachers' Continuous Training, Pact Program, In-serving training, School locus

\section{Resumen}

Este trabajo, de carácter cualitativo, investiga la temática de la formación continuada de profesores del Programa Pacto en cinco escuelas públicas estatales de la región central del RS, cubiertas por la 24a - Coordinadora Regional de Educación (CRE), durante los años 2014 y 2015. La investigación pretende analizar avances que permearon este proceso formativo, a través de la opinión de 25 profesores y de 5 orientadores de estudio. La recolección de datos ocurrió por medio de la observación directa individual no participante anotada en el cuaderno de a bordo, del análisis documental y de la entrevista semiestructurada. Los resultados apuntaron a la construcción de cuatro categorías: el programa Pacto en la visión de los educadores, las expectativas del Pacto, las actividades/metodologías desarrolladas y el papel del orientador de estudios y su formación.

Palabras clave: Formación continua de profesores, Programa Pacto, Formación en servicio, Locus de la escuela

\section{Introdução}

O conjunto das questões sobre formação continuada de professores se apresenta como alvo de análises em eventos (encontros, simpósios, congressos etc.) e em periódicos nacionais e internacionais. Além disso, nas últimas décadas, tem-se testemunhado um aumento contínuo do interesse pelo tema, o que pode ser constatado por meio do levantamento de pesquisas em teses e dissertações, no banco de dados da Coordenação de Aperfeiçoamento de Pessoal de Nível Superior (ANDRÉ, 2000; ROMANOWSKI, 2002; GATTI; BARRETO, 2009).

Nesse escopo, o presente estudo investiga a temática da formação continuada de professores, que foi desenvolvida tendo como objeto o programa de formação continuada do Pacto Nacional pelo Fortalecimento do Ensino Médio (Pacto). A empiria, que tem como problema de investigação - como se dá a formação continuada de professores do programa Pacto em escolas públicas estaduais da região central do RS, abrangidas pela 24a CRE? - visa a analisar avanços que permearam esse processo formativo, por meio da opinião de professores e de orientadores de estudo que participaram dele.

A concepção adotada neste trabalho acerca de formação continuada ressalta a ideia de um processo permanente de construção, de desenvolvimento e de amplitude do professor, bem como que se insere como elemento de socialização e Revista Educação Online, Rio de Janeiro, n. 28, abr-ago 2018, p.145-162 
crescimento pessoal e profissional, capaz de interferir na melhoria de seu trabalho no contexto escolar.

Essa concepção está em sintonia com alguns autores, cujos trabalhos de pesquisa são frequentes na área de educação, entre eles, destacam-se: Candau (1996), Freire (1996), Gatti (2003), Lima (2001), Mazzeu (1998), Nóvoa (1991), Pimenta (2002) e Correa et al. (2017).

A inclusão da formação continuada na constituição da profissão docente tem seu marco em 1985, conforme a Associação Nacional pela Formação dos Profissionais da Educação - Anfope, que discute e analisa a questão das políticas e da importância da formação do professor (ANFOPE, 1994).

$\mathrm{Na}$ Lei de Diretrizes e Bases da Educação Nacional, Lei 9394/96 (BRASIL, 1996), a formação continuada aparece sob várias formas: capacitação em serviço, educação continuada, aperfeiçoamento profissional continuado, programas de capacitação e treinamento em serviço.

Em 2013, com o objetivo de valorizar a formação continuada de professores na rede pública estadual do ensino médio, o Ministério da Educação instituiu, por meio da Portaria Ministerial no 1.140, de 22 de novembro de 2013, o Pacto Nacional pelo Fortalecimento do Ensino Médio - Pacto (BRASIL, 2013), um programa que investe na formação continuada em serviço de professores e que constitui o foco desta pesquisa. Entre os objetivos vislumbrados pelas ações desse programa (BRASIL, 2013, p. 24), estão:

I - contribuir para o aperfeiçoamento da formação dos professores e coordenadores pedagógicos do ensino médio;

II - promover a valorização pela formação dos professores e coordenadores pedagógicos do ensino médio; e

III - rediscutir e atualizar as práticas docentes em conformidade com as Diretrizes Curriculares Nacionais do Ensino Médio - Dcnem.

O programa Pacto também prevê a parceria entre as Instituições de Educação Superior (IES) públicas e as secretarias de educação, bem como a concessão de bolsas para os participantes.

Dessa maneira, o Pacto foi um programa para professores do ensino médio da rede pública de ensino, que se deu por meio de grupos nas escolas, coordenados por orientadores de estudos das próprias instituições. Além disso, foi constituído na forma de um curso de duzentas horas de formação, realizado em duas etapas. 
Os temas debatidos estavam embasados em campos temáticos, de acordo com as Diretrizes Curriculares Nacionais e as Orientações Curriculares do Ensino Médio, organizados por professores pesquisadores com vínculo em universidades públicas, que desenvolvem estudos sobre o ensino médio.

No caso das escolas de nossa investigação, a primeira etapa desse curso ocorreu de abril a julho de 2014 e teve carga horária de 100 horas, entre elas: 50 horas de atividades coletivas e 50 horas de atividades individuais. Essa etapa trouxe como eixo condutor "Os Sujeitos do Ensino Médio e a Formação Humana Integral" e foi composta pelos seguintes campos temáticos/cadernos: "Ensino médio e formação humana integral", "O jovem como sujeito do ensino médio", "O currículo do ensino médio, seus sujeitos e o desafio da formação humana integral", "Áreas de conhecimento e integração curricular", "Organização e gestão democrática da escola" e "Avaliação no ensino médio".

Já a segunda etapa do curso ocorreu de novembro de 2014 a abril de 2015 e teve carga horária de 100 horas, divididas entre 50 horas de atividades coletivas e 50 horas de atividades individuais. Aqui, dando continuidade ao eixo proposto, as temáticas que compuseram os cadernos de formação do Pacto foram a "Organização do Trabalho Pedagógico no Ensino Médio" e as "Áreas de Conhecimento do Ensino Médio".

\section{Metodologia}

A amostra deste estudo foi constituída por 25 professores e cinco orientadores de estudo, que atuam no ensino médio de cinco escolas públicas estaduais, da região central do Rio Grande do Sul (RS), pertencentes à 24a Coordenadoria Regional de Educação (CRE), inseridos no programa de formação continuada de professores Pacto. Essa formação ocorreu nas próprias escolas, no horário da hora-atividade ( $1 / 3$ da carga horária do professor), em turnos da tarde e noite - durante a semana - e aos sábados, pela manhã e tarde.

A 24aㅡ CRE tem sua sede no município de Cachoeira do Sul/RS e está subordinada à Secretaria da Educação do Rio Grande do Sul, cuja sede fica em Porto Alegre/RS. As escolas selecionadas se localizam em quatro municípios Agudo, Dona Francisca, Paraíso do Sul e Restinga Sêca - inseridos na macrorregião centro-oeste do RS, ou também conhecida região central do RS. 
O presente trabalho foi realizado, de acordo com Zanella (2009), como um estudo qualitativo, pois se preocupou com o desdobramento do processo do curso de formação continuada do Pacto, com a descrição e interpretação dos fenômenos observados a partir de vários ângulos, sob o ponto de vista do grupo de professores e orientadores de estudo pesquisados. Além disso, o pesquisador, foi a campo, observou a realidade com os próprios olhos, conviveu com os atores da pesquisa e conheceu o cotidiano de cada uma das cinco escolas investigadas, ao longo dos anos de 2014 e 2015.

Quanto aos procedimentos adotados na coleta de dados, o estudo se calcou no método de investigação denominado estudo de campo (GIL, 2007), uma vez que o pesquisador realizou a maior parte do trabalho pessoalmente, bem como permaneceu o maior tempo possível no cenário da pesquisa, objetivando compreender o contexto da vida real e os mais diferentes aspectos do grupo estudado: professores e orientadores de estudo.

Os instrumentos utilizados na obtenção dos dados foram:

a) A modalidade de observação direta individual não participante, realizada pelo pesquisador/autor e anotada em seu diário de bordo. Foram registrados os momentos observados, com uma descrição dos sujeitos, espaços, acontecimentos e conversas, bem como as reflexões e ideias dos participantes da pesquisa, ocorridas ao longo das duas etapas do Pacto. Os registros foram realizados pelo pesquisador em forma de descrição real, mantendo a maneira como foram ouvidos e observados.

b) A análise documental se deu por meio de fontes primárias - os registros escritos de redações produzidas pelos professores e planejamentos das atividades do Pacto utilizadas pelos orientadores de estudos - e fontes secundárias - os cadernos do Pacto. A análise documental ocorreu ao longo das duas etapas do curso.

c) A entrevista semiestruturada construída pelos pesquisadores se constituiu de questões atinentes à escola, aos professores, às etapas e aos cadernos do Pacto, bem como à opinião sobre alguns temas que envolveram o curso. Ela foi aplicada logo após o término da segunda etapa do Pacto.

As entrevistas tiveram duração média de 30 minutos, foram gravadas em áudio e, posteriormente, transcritas para então serem analisadas. Salienta-se que, na passagem das entrevistas do áudio para a escrita, procurou-se respeitar, dentro 
dos limites possíveis, as características próprias do registo oral. Todavia, foram retificados certos aspectos próprios da oralidade, nomeadamente contrações e repetições de palavras, eventuais incorreções ao nível dos processos de concordância em gênero e/ou número, bem como se omitiram repetições redundantes de palavras. Também se uniformizou o tratamento formal das conversas para evitar discrepâncias nesse nível.

O código utilizado na apresentação dos resultados dos sujeitos participantes da pesquisa foi: $\mathrm{P} 1, \mathrm{P} 2, \ldots, 25$ para os 25 professores e $\mathrm{O} 1, \mathrm{O} 2, \ldots, \mathrm{O} 5$ para os cinco orientadores de estudos que participavam do programa.

Faz-se necessário salientar o caráter interdisciplinar desta pesquisa, uma vez que, em seu universo de 30 sujeitos participantes, encontram-se professores das mais variadas áreas do conhecimento, bem como de diferentes disciplinas.

Quanto à metodologia de análise de dados, a presente pesquisa se utilizou da análise textual discursiva, que se caracteriza um processo de abordagem composto por um ciclo de operações, que se inicia com a desconstrução dos textos ou unitarização dos materiais do "corpus", passa pela reordenação ou categorização das unidades de análise e termina com a comunicação de novas teses ou produção de metatextos (MORAES; GALIAZZI, 2007).

Desse modo, o "corpus" da investigação foi constituído por produções textuais escritas que abarcaram: os registros da observação, realizada pelo pesquisador e anotada em seu diário de bordo; as análises documentais de fontes primárias e secundárias; e as respostas transcritas das entrevistas semiestruturadas.

Com base nessa metodologia de análise, a sistematização dos resultados desta investigação em categorias, criadas pelos pesquisadores, emergiu, inicialmente, de muitas leituras, releituras e um olhar de forma abrangente para os cenários descortinados pelos instrumentos - observações anotadas no diário de bordo e análises documentais - em interação com os elementos do referencial teórico que balizam a pesquisa.

Posteriormente, visando a ratificar e/ou a aprofundar as categorias emergidas anteriormente, utilizaram-se os dados coletados das entrevistas semiestruturadas.

\footnotetext{
1 "Corpus": De acordo com Bardin (1977), o "corpus" é um conjunto de documentos submetidos aos procedimentos analíticos.
} 
Nesse processo, destacam-se também o desvelamento e a construção de novas categorias.

\section{Resultados e discussão}

Os resultados são apresentados sob a forma de categorias, criadas pelos pesquisadores de acordo com a metodologia da análise textual discursiva.

\subsection{O programa Pacto na visão dos educadores}

As ideias acerca do programa Pacto foram evidenciadas no depoimento de alguns professores e orientadores de estudos, anotadas no diário de bordo do pesquisador, numa das primeiras discussões acerca do seu funcionamento, representativos do conjunto. Algumas respostas foram:

O Pacto tem como foco discutir uma nova escola, um novo perfil de professor, um novo currículo. (P13)

O curso não tem nenhuma receita pronta, pois nós [professores] seremos os protagonistas da nossa realidade através da troca de ideias. (P15)

A formação será dentro da própria escola, no tempo da hora-atividade [1/3 da carga horária] da nova jornada de trabalho. (O5)

Percebe-se, na fala desses profissionais, que o Pacto é uma formação continuada em serviço dos docentes, que acontece no "chão da escola", no tempo da hora-atividade (1/3 da carga horária do professor), pois valoriza os saberes produzidos no seu cotidiano e promove a construção de caminhos para a autonomia escolar, por meio do compartilhamento de ideias entre os professores.

Corroborando nesse prisma, Candau (1996, p. 144) adverte que a escola deve ser considerada como locus de formação continuada, a fim de "superar o modelo clássico de formação continuada e construir uma nova perspectiva na área de formação continuada de professores". Além disso, nessa direção, Correa et al. (2017, p. 88) também apontam para "a centralidade da escola como locus privilegiado para a formação e reflexão".

Nota-se que o Pacto não é uma "receita pronta", que irá resolver todos os problemas do ambiente escolar, mas uma orientação que fomentará a discussão e o aprimoramento da práxis entre os docentes, propiciando aprofundamento e atualização dos conceitos e práticas fundamentais que norteiam o ensino. 


\subsection{As expectativas dos professores com relação ao Pacto}

Esta categoria destaca quais foram as expectativas, os anseios $\mathrm{e}$ possibilidades dos professores em relação ao programa Pacto. Seguem alguns depoimentos de professores, na entrevista semiestruturada, representativos do conjunto:

O que eu esperava do Pacto era a forma assim... de como trabalhar com os alunos novas metodologias, de como sentar e planejar nas áreas. (P21)

Esperava do Pacto um momento de encontro, de discussão, de reflexão. E eu acho que a gente precisava desse momento para poder discutir o que tava acontecendo na escola e tentar planejar melhor aquilo ali no conjunto. (P22)

O Pacto seria um momento de estudos e de leituras..., que fosse ajudar o nosso grupo de professores num trabalho mais interdisciplinar, por área... até porque a nossa formação é tudo por disciplina. (P24)

Esperava mais atividades práticas para a sala de aula, pois a gente tá muito acostumado com a aula tradicional, do quadro e giz. (P25)

Dos fragmentos acima, é possível perceber que os professores tinham grandes expectativas em relação ao Pacto, entre as mais citadas, está a questão do trabalho coletivo e interdisciplinar por áreas do conhecimento. Os professores sinalizam que o Pacto poderia resolver esse problema, porém, deve-se partir da compreensão de que não existe nenhuma receita para essa prática pedagógica.

Por mais que a formação desses profissionais tenha sido tradicional e por disciplina, como apontam alguns educadores em suas falas, é necessária uma concepção mais ampla do fazer pedagógico acerca do trabalho interdisciplinar por áreas do conhecimento. Nesse sentido, acredita-se que é na convivência do coletivo dos sujeitos envolvidos no processo educativo, bem como no diálogo, na discussão, na reflexão e no planejamento participativo entre eles, que essa problemática pode ser solucionada.

No tocante à tarefa de planejar, vale destacar a contribuição de Gandin (1995, p. 28-29), ao ressaltar que o planejamento participativo, de acordo com a justiça social, congrega a participação de todos no poder e representa a construção conjunta dos envolvidos.

Portanto, ao destacar o modelo de planejamento participativo enquanto ação coletiva na organização do trabalho interdisciplinar por áreas do conhecimento, 
convocam-se os professores a assumirem papel ativo nessa discussão, e não apenas a serem meros espectadores ou esperar que o Pacto traga a solução para tal.

\subsection{As atividades/metodologias desenvolvidas}

As atividades/metodologias desenvolvidas durante as duas etapas do Pacto foram construídas por meio de um rol de atividades, conforme análise documental, que envolveram: dinâmica "a espiral"; leitura individual e coletiva; levantamento das concepções prévias dos docentes por meio da problematização; debate, discussão e reflexão; síntese; formação de grupos; vídeo; explanação com apoio de slides; questionário; tabulação de dados; música; filme; confecção de cartazes; construção de painel por meio de recorte e colagem; construção de memorial ou autobiografia profissional; socialização de registros; compartilhamento de reflexões; desenho coletivo; autoavaliação; tirinha; apresentação oral; dramatização; elaboração de um plano de ação; trabalho de investigação; realização de pesquisa; dinâmica da "borboleta" - construção do jardim do Pacto; dinâmica do "jornal"; produção de redação; diálogo; construção de projetos interdisciplinares; roda de conversa; construção de mapa conceitual; e oficina.

Percebe-se uma diversidade de metodologias utilizadas e de atividades desenvolvidas durante as duas etapas do processo de formação continuada de professores da presente investigação. Isso tudo, por sua vez, colaborou para um ambiente propício de troca, diálogo e interação entre os docentes participantes, bem como, oportunizou-os que voltassem a estudar e refletir sobre o trabalho em sala de aula, além de fomentar o planejamento coletivo e interdisciplinar.

Esses aspectos ficam evidentes nos seguintes relatos, coletados na entrevista semiestruturada de alguns professores e orientadores de estudos, representativos do conjunto:

As atividades do Pacto proporcionaram aos professores um ambiente descontraído, com muito bate papo e troca de ideias. (O1)

As práticas realizadas durante os encontros do Pacto propiciaram momentos enriquecedores aos professores, que puderam interagir e trocar "figurinhas" sobre o que estavam fazendo em sala de aula. (O4)

O curso é bom, pois eu que tava parada há tempo, voltei a estudar e me atualizar com estes cadernos do Pacto. (P22) 
[...] Por exemplo, no Pacto, a gente tava trabalhando de uma forma diferenciada, dinâmicas novas, trabalhos em conjunto, formas menos conteudistas. (P23)

$\mathrm{Na}$ época, a gente reclamava que tinha que vir aqui aos sábados, mas, hoje, reconhecem que foi o único momento que a gente parou, discutiu e refletiu de verdade. (P24)

Enquanto o Pacto existia, nós sentávamos, discutíamos e trocávamos ideias do que ia acontecer lá na sala de aula, e os professores acabavam um ajudando o outro para que aquele planejamento interdisciplinar, aquele tema, fosse efetivo lá naquela turma, seja de qual área o professor fosse. Hoje, os professores conversam menos, sentam menos junto pra planejar, pra discutir. (P25)

Em consonância com o exposto acima, a prática pedagógica presente nas atividades desenvolvidas durante o Pacto vão ao encontro do paradigma da racionalidade dialógica (FREIRE, 1983, 1996). Freire defendia a necessidade de uma construção de conhecimento entre os pares, por meio da interdisciplinaridade e do diálogo, em atividades de grupo, com incentivo à participação e ao exercício da reflexão crítica. Além disso, ele sinaliza, como elemento balizador dessa construção, uma perspectiva metodológica/curricular caracterizada pelos temas geradores, em sua Pedagogia do oprimido (FREIRE, 1987).

Em sua proposta, Freire (1987) pressupõe um estudo da realidade do educando, feita pelo educador por meio da organização dos dados. Nesse processo, surgem os temas geradores, extraídos da problematização da prática de vida dos estudantes. Nesse sentido, para exemplificar tais pressupostos, a atividade/metodologia desenvolvida a seguir apresenta uma construção de projeto interdisciplinar que foi trabalhada numa das escolas investigadas.

A temática escolhida na referida escola, que foi construída e implementada em 2015, estava relacionada ao meio ambiente e foi chamada de "Desperdício do lixo". Acompanhe o depoimento da orientadora de estudos do Pacto dessa escola, contando como se deu a escolha e implementação de tal temática:

A temática do "Desperdício do lixo" surgiu depois de realizarmos uma pesquisa com a comunidade por meio de entrevistas e questionários. Reunimos os pais, alunos e professores e, de forma conjunta, optamos por essa temática.

[...]

O desperdício do lixo é um dos problemas que afeta a realidade do nosso munícipio, pois aqui a gente tem o rio Jacuí, que passa aqui do lado da cidade. Um rio muito importante para o sustento das famílias, principalmente, para irrigação das lavouras de arroz.

$[\ldots]$

Revista Educação Online, Rio de Janeiro, n. 28, abr-ago 2018, p.145-162 
Aí tem muita gente que joga o lixo dentro dele, então, a gente pensou em algo para conscientizar os alunos e a comunidade sobre essa questão do desperdício e descarte do lixo, além de mostrar a eles que têm materiais que podem ser reciclados. $[\ldots]$

O tema gerador foi trabalhado, ao longo de todo ano de 2015, por todas as turmas do ensino médio.

$[\ldots]$

A gente sentou e planejou interdisciplinarmente, em conjunto, os conteúdos e as atividades do projeto temático do Desperdício do Lixo.

$[\ldots]$

A gente bolou até uma gincana da solidariedade, em que uma das tarefas era recolher a maior quantidade de lixo reciclável das ruas da nossa cidade. Depois, a gente doou uma parte para a prefeitura para fazer os arranjos de Natal, que eram os "litrões PET". O restante, que eram latinhas, a gente vendeu para poder ajudar a consertar o telhado da escola. Então, a gente trabalhou em cima dessa temática que envolve a comunidade.

Observa-se, a partir desse depoimento, que a escolha dessa temática vai ao encontro das ideias preconizadas por Paulo Freire (1987), uma vez que o tema está relacionado à realidade da comunidade e representa um problema significativo a ser resolvido naquele contexto. Além disso, a temática foi escolhida com a participação cooperativa e conjunta de alunos, pais e professores, bem como contou com 0 trabalho interdisciplinar dos educadores da escola.

Veja a seguir como foi o planejamento interdisciplinar por áreas do conhecimento da temática e as atividades desenvolvidas. O material foi coletado a partir da análise documental:

CIÊNCIAS DA NATUREZA:

- Os problemas/poluição do lixo no meio ambiente;

- Os tipos de lixos produzidos;

- A reciclagem;

- A preservação do meio ambiente;

- Cuidados com a saúde nas doenças transmitidas pelo lixo acumulado;

- Alternativas de disposição final: lixões, aterro controlado, aterro sanitário, incineração, usinas de triagem e compostagem e reciclagem;

- Transformações de energia geradas pela reutilização do lixo;

- Tecnologias;

- Saúde do trabalhador;

- Defesa do consumidor;

- Qualidade de vida;

- Conpet - Programa Nacional de Racionalização do Uso dos Derivados de Petróleo e do Gás Natural

CIÊNCIAS HUMANAS:

- Compreensão e avaliação das questões relativas ao lixo, sob o ponto de vista ético para exercer a cidadania com responsabilidade, integridade e respeito;

- Participação da sociedade civil;

- Educação e mudança de hábitos; 
- Ocupação da zona urbana de forma desorganizada e falta de infraestrutura adequada;

- Questões ambientais, urbanísticas, tecnológicas, políticas, sociais e econômicas;

- Industrialização;

- Desiquilíbrios sociais;

- Degradação ambiental.

MATEMÁTICA:

- Trabalhar problemas, gráficos e tabelas que envolvam dados relativos ao assunto;

- Transformações das unidades de comprimento/profundidade, de massa e de volume.

- Porcentagens e percentuais;

- Atividade: Com base nos dados da reportagem do jornal $O$ Globo, edição publicada em 27/05/2013, que dizia "[...] Em dez anos, de 2003 a 2012, a geração de lixo [no Brasil] por pessoa aumentou de $955 \mathrm{~g}$ por dia para 1,223 kg. [...]", calcule a quantidade de lixo que é gerada diariamente, em toneladas, pelos 3.374 habitantes do município de Dona Francisca (IBGE, $1^{\circ}$ de julho de 2015).

\section{LINGUAGENS:}

- Leitura de textos em livros, revistas, jornais sobre o assunto;

- Exposição de ideias e argumentação;

- Produção de textos variados: relatórios, listas, panfletos, cartazes, poemas, acrósticos, murais etc.;

- Arte que vem do lixo (confecção de vestidos, brinquedos, utensílios domésticos, desenhos, arranjos de Natal etc.).

ATIVIDADES DESENVOLVIDAS EM CONJUNTO COM TODAS AS ÁREAS:

- Construção de maquetes;

- Montagem de cartazes com textos;

- Realização de pesquisas em grupos;

- Coleta de informações sobre o destino e desperdício do lixo, por meio de entrevistas com profissionais gabaritados na prefeitura e na Emater [Empresa de Assistência Técnica e Extensão Rural];

- Buscaram-se parcerias com órgãos que realizam a coleta dos materiais;

- Conhecer o lixão da comunidade;

- Aprender e ensinar a reutilizar o lixo;

- Apresentação da campanha desenvolvida por todos os alunos para a comunidade no geral;

- Divulgação do trabalho realizado em sala de aula de forma dinâmica e atrativa através de apresentações teatrais, músicas, paródias;

- Desfiles e caminhada;

- Realização de oficinas de reciclagens e reutilização de garrafas PET.

Evidencia-se, mediante a análise do projeto de uma das escolas investigadas, o caráter interdisciplinar da presente pesquisa, a realização de um trabalho coletivo e que estabelece relações entre as diferentes áreas do conhecimento, o planejamento participativo entre os envolvidos, a concretização da articulação entre teoria e 
prática, bem como um alinhamento dessa atividade com a perspectiva metodológica/curricular dos temas geradores balizados por Paulo Freire (1987).

No que tange ao rol de atividades desenvolvidas durante o Pacto, destaca-se, entre as várias citadas, a construção do memorial ou autobiografia profissional. Por meio dela, foi possível realçar o recurso de histórias de vida, na qual os professores puderam expor suas práticas e experiências vivenciadas ao longo da carreira. Nessa atividade, percebeu-se bastante envolvimento por parte dos educadores, como a emoção de muitos deles, ao rememorar fatos e acontecimentos de sua trajetória pessoal e profissional. Isso, por sua vez, possibilitou o resgate de experiências e práticas pedagógicas que puderam servir como parâmetros para outros professores.

Essa atividade [construção do memorial] foi uma das que eu mais gostei, pois foi um momento em que pude relembrar toda minha história profissional e pessoal. Até chorei de emoção, mas foi interessante, pois pode servir de exemplo para meus colegas que estão começando agora. (P25)

A atividade do memorial foi bem rica para mim, pois consegui aprender algumas práticas novas, ouvindo os colegas contarem suas experiências profissionais. (P21)

Corroborando a importância das histórias de vida no processo de formação docente, Josso (2004) aponta que elas auxiliam a pensar a formação do professor para atuar frente aos novos papéis que vem sendo solicitado da instituição escola.

\subsection{O papel do orientador de estudos e sua formação}

Nesta categoria, faz-se necessário ressaltar a atuação do orientador de estudos como formador e articulador das ações do Pacto nas escolas. O que se observou na totalidade das cinco escolas investigadas foi que o coordenador pedagógico assumiu a função de orientador de estudos e contribuiu de forma positiva para uma ressignificação do seu papel no interior da escola. Os depoimentos a seguir comprovam isso:

O papel de nossa coordenadora pedagógica como orientadora de estudos do Pacto foi fundamental, pois nos auxiliou no entendimento das abordagens teóricas e também no desenvolvimento e implementação de projetos interdisciplinares. (P21)

[...] nossa coordenadora pedagógica nos ajudou bastante durante o Pacto, porque conseguiu unir os professores e, com seu método da reflexão-ação, favoreceu a aplicação da teoria nas nossas atividades práticas. (P25)

Como se pode perceber, o trabalho desempenhado pelo coordenador pedagógico como orientador de estudos no Pacto foi de suma importância, uma vez Revista Educação Online, Rio de Janeiro, n. 28, abr-ago 2018, p.145-162 
que suas ações mediadoras e articuladoras conseguiram congregar o coletivo de professores e ampliar suas práticas pedagógicas. Além disso, o fazer desse profissional corroborou uma visão dialógica e dialética no exercício de ação-reflexãoação.

Nesse sentido, uma das orientadoras de estudos deixa claro em seu depoimento, o papel por ela desempenhado:

Inicialmente, eu tinha um certo receio de atingir os objetivos do Pacto, de construir algo melhor dentro da realidade de escola..., de trabalhar com os professores, mas depois, eu fui gostando, porque é importante trabalhar no coletivo com os professores e ver que eles conseguiram fazer algumas atividades interdisciplinares. (O4)

A formação dos orientadores de estudo ocorria mensalmente, tanto na coordenadoria de educação, a 24a $\mathrm{CRE}$ (com formadores regionais), quanto nas IES, como a Universidade Federal de Santa Maria (com os formadores das IES, geralmente, docentes das licenciaturas).

Para esclarecer essas informações, recorreu-se às falas de alguns professores e orientadores de estudos:

A orientadora de estudos teve a formação juntamente com as outras escolas da região na CRE e na UFSM. Nessas formações, eles planejavam o cronograma para depois trabalhar conosco. Os encontros da orientadora de estudos eram mensais. Nesses encontros, eles estudaram os cadernos do Pacto, para depois repassar aos professores. (P22)

Nos reuníamos na CRE e na universidade, para fazer o planejamento conjunto e para discutirmos a metodologia. Depois cada uma foi adequando o planejamento e a metodologia para sua escola, na sua realidade. (O3)

Ela ia lá em Santa Maria, com a professora X, ela fazia a formação lá e depois fazia a multiplicação aqui na escola. (P21)

A formação acontecia na universidade e na coordenadoria. Lá, nós aprofundávamos as questões teóricas e fazíamos a avaliação do que já havia passado. (O4)

Desses depoimentos, é possível perceber que tanto os orientadores de estudos quanto os formadores regionais e das IES trabalharam de forma coletiva, colaborativa e articulada, em todas as etapas que envolveram a formação: planejamento, metodologia, aprofundamento, acompanhamento e avaliação.

Portanto, nessa categoria, ressaltou-se o papel central do coordenador pedagógico como orientador de estudos do Pacto nas escolas investigadas. É importante frisar que esse profissional exerce um papel de relevância no tocante à 
formação continuada do professor, e isso se deve ao trabalho que ele realiza de planejamento e acompanhamento na implementação de projetos escolares, oferecendo apoio e sustentação às equipes de educadores na execução dessas atividades.

No que tange a esse enfoque, Placo e Almeida (2003, p. 57-58) enfatizam que "uma função fundamental do coordenador pedagógico é cuidar da formação e do desenvolvimento profissional dos professores", de forma que possa ser superada a fragmentação entre teoria e prática.

Fica evidente, assim, que a figura do coordenador pedagógico contribui efetivamente para a qualidade do processo educativo nas escolas, fazendo isso, sobretudo, por meio do acompanhamento e da formação continuada dos professores.

\section{Considerações finais}

Os resultados apresentados pela presente pesquisa sinalizam os seguintes avanços permeados durante o programa Pacto no contexto de cinco escolas públicas estaduais da região central do RS, abrangidas pela 24a Coordenadoria Regional de Educação (CRE), durante os anos de 2014 e 2015:

- O Pacto se constituiu numa formação em serviço, balizada pela resolução de problemas reais no contexto escolar, potencializando a hora-atividade do professor (1/3 da carga horária) e contribuindo para uma nova cultura de formação, balizada pela construção coletiva e interdisciplinar.

- A formação do Pacto aconteceu no locus da escola, ou seja, no "chão da escola", valorizando o processo de reflexão na ação, bem como os saberes construídos e compartilhados pelos educadores no cotidiano do ambiente de trabalho.

- A diversidade de metodologias utilizadas, durante a realização do Pacto, favoreceu a democratização dos seus participantes, uma vez que apoiou a reflexão crítica e coletiva sobre a sua prática docente, numa discussão construtiva e respeitosa, e ofereceu um espaço de formação continuada para a promoção do trabalho em grupo, da interação, do diálogo de saberes e da construção de laços de confiança entre seus atores. 
- A metodologia do Pacto favoreceu uma avaliação contínua, pois as produções dos cursistas serviam de parâmetro para análise das estratégias propostas.

- A metodologia de construção de projetos contribuiu para o caráter interdisciplinar da presente pesquisa, para a realização de um trabalho coletivo e que estabelece relações entre as diferentes áreas do conhecimento, para o planejamento participativo entre os envolvidos, para a concretização da articulação entre teoria e prática, bem como para um alinhamento dessa atividade com a perspectiva metodológica/curricular dos temas geradores balizados por Paulo Freire (1987).

- A atuação do coordenador pedagógico como orientador de estudos, na totalidade das instituições investigadas, contribuiu para uma ressignificação do seu papel no interior da escola.

- Articulação conjunta entre os orientadores de estudos, os formadores regionais e as IES, em todas as etapas que envolveram a formação.

O estudo é de grande importância para o processo educacional, pois, mesmo focando no projeto do Pacto, acaba apresentando um panorama geral, válido para o grupo de professores que atuam na rede de ensino público estadual, podendo ser direcionada a outros grupos.

Assim, é de suma importância que as políticas públicas de âmbito educacional e os pesquisadores da área incentivem o fomento dos processos de formação continuada de professores, bem como os compreendam para que se possa ajudar os educadores na construção da sua identidade, do seu caminho pessoal e profissional, em seu projeto de vida, no desenvolvimento das suas habilidades e competências, de maneira que lhes permitam encontrar seus espaços pessoais, sociais e se tornarem cidadãos realizados e produtivos.

Desse modo, a formação continuada em serviço, no locus da escola, pode contribuir para que exista um conjunto de ações voltadas à formação do professor, mas, sobretudo, haja uma progressividade do que o professor faz do seu trabalho, das suas práticas, dos seus saberes acumulados no exercício da docência e nas suas próprias investigações teóricas. Além disso, ele passa a enxergar a possibilidade de desenvolvimento profissional centrada na escola enquanto instituição de trabalho. 


\section{Referências bibliográficas}

ANDRÉ, M. E. D. A. de. A pesquisa sobre formação de professores no Brasil, 19901998. In: ENCONTRO NACIONAL DE DIDÁTICA E PRÁTICA DE ENSINO, 10., 2000, Rio de Janeiro. Anais... Rio de Janeiro: Uerj, 2000. p.83-89

ASSOCIAÇÃO NACIONAL PELA FORMAÇÃO DE PROFISSIONAIS DA EDUCAÇÃO. In: ENCONTRO NACIONAL, 7., 1994, Niterói:. Anais... Rio de Janeiro: Anfope, 1994. p. 25.

BARDIN, L. Análise de conteúdo. Lisboa: Edições 70, 1977.

BRASIL. Ministério da Educação. Secretaria de Educação Profissional e Tecnológica. Leis e Decretos. Lei de Diretrizes e Bases da Educação Nacional, no 9.394, de 20 de dezembro de 1996. Disponível em: <http://www.planalto.gov.br/ccivil_03/leis//9394.htm>. Acesso em: 30 ago 2015.

. Portaria $n^{\circ} 1.140$, de 22 de novembro de 2013. Institui o Pacto Nacional pelo Fortalecimento do Ensino Médio e define suas diretrizes gerais, forma, condições e critérios para a concessão de bolsas de estudo e pesquisa no âmbito do ensino médio público, nas redes estaduais e distrital de educação. Diário Oficial da União, Brasília, DF, no 238, segunda-feira, 9 de dezembro de 2013. p. 24-25. Disponível em:

$<$ http://portal.mec.gov.br/index.php?option=com_docman\&view=download\&alias=15 069-pacto-dou-1-2\&category_slug=janeiro-2014-pdf\&ltemid=30192>. Acesso em: 04 nov 2015.

CANDAU, V. M. F. A formação continuada de professores: tendências atuais. In: REALI, A. de M. R.; MIZUKAMI, M. da G. N. (Orgs.). Formação de professores: tendências atuais. São Carlos: EDUFSCar, 1996. p. 139-152.

CORREA, L. M. et al. Escola como locus da formação continuada e o Pacto Nacional pelo Fortalecimento do Ensino Médio: efeitos na vida dos professores. Em Aberto, v.30, n.98, p.87-104, jan-abr 2017. Disponível em: <http://dx.doi.org/10.24109/2176-6673.emaberto.30i98.3198>. Acesso em: 26 jan 2018.

FREIRE, P. Extensão ou comunicação? 7ª̣ed. Rio de Janeiro: Paz e Terra, 1983.

. Pedagogia da autonomia: saberes necessários à prática educativa. 9ª̣ed. São Paulo: Paz e Terra, 1996. (Coleção Leitura).

. Pedagogia do oprimido. 17ª ed. Rio de Janeiro: Paz e Terra, 1987.

GANDIN, D. A prática do planejamento participativo: na educação e em outras instituições, grupos e movimentos dos campos cultural, social, político, religioso e governamental. Petrópolis, RJ: Vozes, 1995.

GATTI, B. A. Formação continuada de professores: a questão psicossocial. Cadernos de Pesquisa, n.119, p.191-204, 2003. Disponível em: $<$ http://www.scielo.br/scielo.php?script=sci_arttext\&pid=S010015742003000200010\& Ing=pt\&nrm=iso $>$. Acesso em: 06 set 2015.

; BARRETO, E. S. de S. Professores do Brasil: impasses e desafios. Brasília: UNESCO, 2009. 
GIL, A. C. Métodos e técnicas de pesquisa social. 5ed. São Paulo: Atlas, 2007. JOSSO, M-C. Experiências de vida e formação. São Paulo: Cortez, 2004.

LIMA, M. S. L. A formação contínua do professor nos caminhos e descaminhos do desenvolvimento profissional. Tese (Doutorado em Educação) - Centro de Educação, Universidade de São Paulo, São Paulo, 2001.

MAZZEU, F. J. C. Uma proposta metodológica para a formação continuada de professores na perspectiva histórico-social. Caderno CEDE, v.19, n.44, p. 59-72, abr 1998. Disponível em:

<http://www.scielo.br/scielo.php?script=sci_arttext\&pid=S010132621998000100006\& lng=pt\&nrm=iso $>$. Acesso em: 06 set 2015.

MORAES, R.; GALIAZZI, M. C. Análise textual discursiva. ljuí: Ed. Unijuí, 2007.

NÓVOA, A. Concepções e práticas da formação contínua de professores: In:

(Org.). Formação contínua de professores: realidade e perspectivas. Portugal: Universidade de Aveiro, 1991. p. 15-38.

PIMENTA, S. G. Professor reflexivo: construindo uma crítica. In: PIMENTA, S. G. e GHEDIN, E. (Orgs.). Professor reflexivo no Brasil: gênese e crítica de um conceito. São Paulo: Cortez, 2002. p. 12-52.

PLACCO, V. M. de S.; ALMEIDA, L. R. O coordenador pedagógico e o cotidiano da escola. São Paulo: Loyola, 2003.

ROMANOWSKI, J. P. As licenciaturas no Brasil: um balanço das teses e dissertações dos anos 90. Tese (Doutorado em Educação) - Centro de Educação, Universidade de São Paulo (USP), São Paulo, 2002.

ZANELLA, L. C. H. Metodologia de estudo e de pesquisa em administração. Florianópolis; Brasília: Departamento de Ciências da Administração/UFSC; CAPES; UAB, 2009. 